\section{CAN YOU SEAL 20,000 MOLARS?}

A project called 'Seal Cambodia' is seeking self-funded volunteer dentists, dental hygienists, dental therapists and senior dental students to go to Cambodia, Southeast Asia, for one to two weeks to work in primary schools and help achieve a goal of sealing 20,000 children's first permanent molars in a year.

Seal Cambodia is a three-year project to save children's teeth in a country where the levels of caries are among the highest in the world ( $\mathrm{dmft}$ of 8-10 at age five).

Callum Durward, Chair of the Global Child Dental Fund (Cambodia), said: 'We know this project will make a huge difference to the dental health of these children - most of whom presently face extraction of their 6 s by the time they reach high school'.

The project can arrange to collect volunteers from the airport, accommodation, local sightseeing, transport to and from schools, and assistants to work with you. Training on how the programme works and the protocols for GIC sealant placement will be given. Instruments and materials will be provided.

Email sealcambodia@hotmail.com; for other dental opportunities for volunteers in Cambodia or to donate used burs or other items email gcdfundcambodia@hotmail.com.

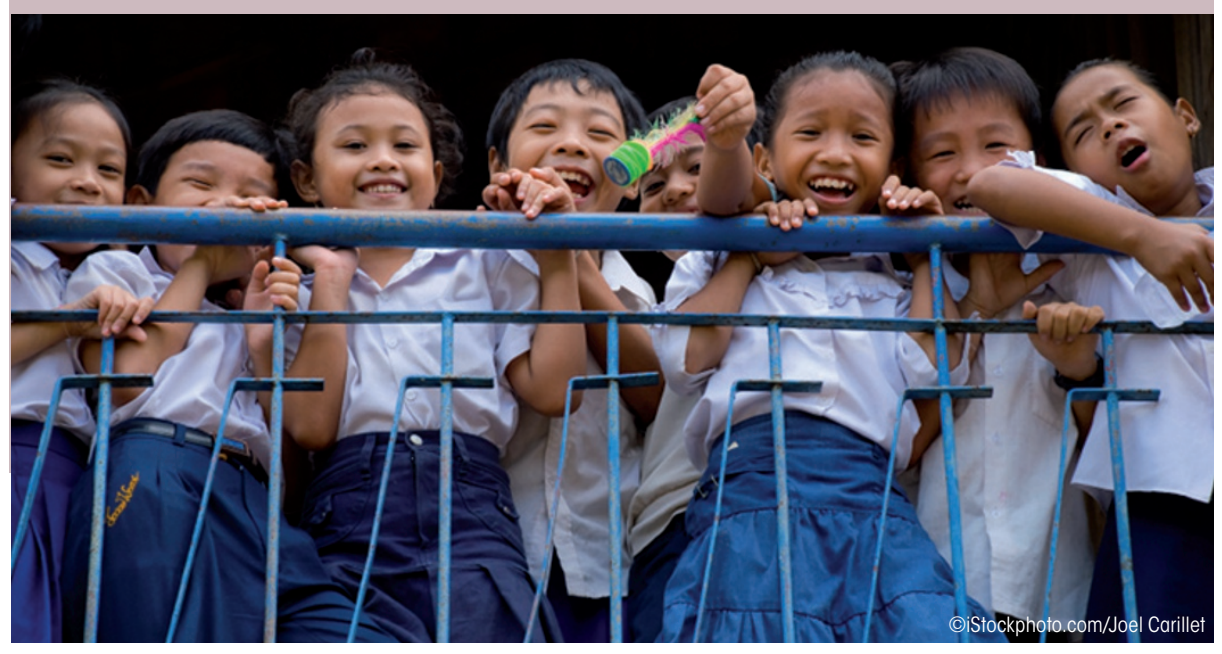

\section{COMMITTED HYGIENIST BECOMES PRESIDENT}

Julie Rosse was installed as new President of the British Society of Dental Hygiene and Therapy (BSDHT) at the BSDHT's Oral Health Conference in Liverpool in November. Julie is successor to Sally Simpson (pictured, left, with Julie).

Julie qualified as a dental hygienist at the Eastman Dental Institute in London in 1995 and worked in community dental health before moving into general practice. She has been a committed member of BSDHT since her student days and has held the post of President Elect since 2010 during which time she has continued as Regional Group Co-ordinator, a responsibility she will retain as President. Julie said that she 'always believed that the strength of BSDHT lies not only in the hard work and commitment of the members of Council and Executive but also of those who work tirelessly for us at grass roots level within our Regional Groups.' She also said that she hopes to carry on the 'fabulous work' of her predecessor.

\section{HYGIENIST FORUM CELEBRATES 1,000TH MEMBER}

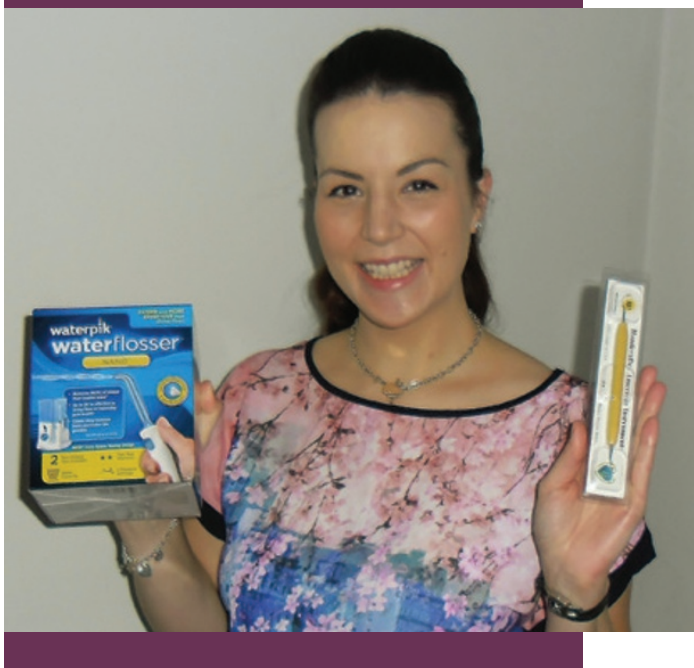

Louise Clark, a student dental hygienist at the Eastman, has become the $1,000^{\text {th }}$ member of the online forum hygienist. co.uk.

Hygienist.co.uk in its present format is now ten years old and is hosted and run by its founder John Stanfield MSc RDH, a dental hygienist with over 30 years' experience and several awards under his belt.

Hygienist.co.uk allows members of the dental team to discuss matters affecting the profession of dental hygiene and wider issues affecting dentistry as a whole, in a secure environment. Topics range from direct access to classification of furcations to blockages of airflow tips and even sometimes just to letting off a little steam in an understanding environment. It also serves to educate and mentor those who, because of the way hygienists work (often the only hygienist in the practice), may find it a lonely existence and do not have peers to bounce ideas off.

Louise is pictured with her gifts supplied by Hygienist.co.uk and Swallow Dental of a Waterpik Nano and a Montana Jack sickle scaler (PDT).

\section{DCP COURSE DIRECTORY}

The summer issue of Vital will feature our annual DCP course directory. If you would like your institution, course or training event included, please send the details to vitaleditorial@nature.com or write to Vital, BDJ Editorial, 4-6 Crinan Street, London, N1 9XW. 